\title{
(2) OPEN ACCESS \\ Case of cerebellar ataxia successfully treated by virtual reality-guided rehabilitation
}

\author{
Kazuhiro Takimoto, ${ }^{1}$ Kyohei Omon, ${ }^{1,2}$ Yuichiro Murakawa, ${ }^{3,4}$ Hideo Ishikawa ${ }^{5}$
}

\begin{abstract}
${ }^{1}$ Rehabilitation Center, Eishinkai Kishiwada Rehabilitation Hospital, Kishiwada, Osaka, Japan

${ }^{2}$ Department of Cognitive Behavioral Science, Kyoto University Graduate School of Human and Environmental Studies, Kyoto, Japan ${ }^{3}$ Department of Medical Device Development, mediVR Inc, Toyonaka, Japan ${ }^{4}$ Division of Occupational Therapy, Department of Human Health Sciences, Graduate School of Medicine, Kyoto University, Kyoto, Japan ${ }^{5}$ Hemoptysis and PulmonaryCirculation Center, Eishinkai Kishiwada Rehabilitation Hospital, Kishiwada, Osaka, Japan
\end{abstract}

\section{Correspondence to} Mr Kazuhiro Takimoto takimoto@japanscr.org

Accepted 2 May 2021

\section{Check for updates}

(C) BMJ Publishing Group Limited 2021. Re-use permitted under CC BY-NC. No commercial re-use. See rights and permissions. Published by BMJ.

To cite: Takimoto $\mathrm{K}$, Omon $\mathrm{K}$ Murakawa Y, et al. BMJ Case Rep 2021;14:e242287. doi:10.1136/bcr-2021242287

\section{SUMMARY}

A male patient in his 40s was transferred to our hospital for rehabilitation of ataxia after right cerebellar and brainstem infarction. After 3 weeks of conventional physical therapy, his activities of daily life successfully improved with an increase in the functional impedance measure from 101 to 124 . However, he still fell short of gaining a higher level of balance function, which was necessary for his job as a standup forklift driver. We introduced virtual reality-guided balance training. The training was performed for approximately $40 \mathrm{~min}$ on weekdays for 2 weeks. As a result, the Scale for the Assessment and Rating of Ataxia score decreased from 5 to 1, Functional Balance Scale score improved from 48 to 56, and Mini-Balance Evaluation Systems Test score increased from 20 to 28. The trunk sway disappeared clinically. He regained confidence and returned to work after an additional 2 weeks of physical therapy.

\section{BACKGROUND}

Ataxia is defined as impaired coordination in the absence of motor paralysis or reduced consciousness, which impedes an individual's ability to perform voluntary movements, making them unable to control their direction, force and speed. $^{1-3}$ Cerebellar ataxia develops in a majority of patients with cerebellar stroke, with an estimated prevalence ranging from $51.3 \%$ to $67.5 \% .^{45}$ The loss of balance is one of the critical symptoms of cerebellar ataxia that should be addressed by active intervention since it not only causes clumsiness and sluggishness in limb movements but also symptoms like gait abnormalities can interfere in all aspects of life, including activities of daily living (ADLs) and social activities. ${ }^{67}$ Numerous training exercises to improve balance are available, including stepping, one-leg standing and ball-related and discrelated exercises; however, they have drawbacks such as monotony and challenges adjusting difficulty level. For resolving these issues, researchers overseas have begun to apply virtual reality (VR) technology in rehabilitation programmes targeting balance impairments; systematic reviews on VR-guided training's effectiveness in improving balance have already been published after stroke or in elderly. ${ }^{8} 9$ However, there is insufficient evidence for the treatment of high-level balancing ability in the working generation. In Japan, mediVR KAGURA, a medical device designed for VR rehabilitation, was approved for clinical use in March 2019. ${ }^{1011}$ In this report, we share our experience of a patient who developed cerebellar ataxia following a cerebellar/brainstem infarction, whose ataxia and balance were successfully improved by VR-guided rehabilitation using this device.

\section{CASE PRESENTATION}

A middle-aged man in his 40 s was affected by a right cerebellar/brainstem infarction. Before the stroke, he had been employed in the warehouse logistics, an environment requiring high levels of standing balance for operating forklifts. One day, he suddenly fell at his residence and was then rushed to the hospital. On arrival, consciousness disturbance, persistent gaze deviation, left haemiplegia and right cerebellar ataxia were noted. Diffusion-weighted cranial MRI performed the same day revealed an infarct in the right cerebellum and brainstem (figure 1). Following acute treatment and care, the patient was transferred to our hospital on the 37 th day after onset for recovery-phase rehabilitation.

\section{INVESTIGATIONS}

No obvious motor paralysis was noted at the time of transfer, and he was able to walk unassisted. However, cerebellar ataxia presenting as a rigid gait pattern was noted, with the patient locking his (left) knee during the left stance phase and shuffling the front of his (left) foot during the left swing phase. Additionally, during quick stepups, he required assistance owing to wobbling outside his control. His ADL performance was rated as 'independent' for all activities except for transferring and moving, where he was rated as 'requiring supervision' for safety concerns. Early return to work was the rehabilitation need of highest priority, as the patient was the main provider of his household.

\section{TREATMENT}

For the first 3 weeks after admission to our hospital, the patient underwent a standard physical therapy (PT) programme focusing on balance training (unassisted step ups) and functional gait training (changing direction), with the goal of independent locomotion without assistance within the facility. This programme resulted in improved ADL functioning, including an increase in Functional Independence Measure total score from 101 to 124 pts; however, it did little to improve his coordination and balance-related issues (table 1).

Standard PT was supplemented with a voluntary rehabilitation exercise, which employed a VR medical device ('VR rehabilitation' below) initiating on the 23rd day of inpatient care at our hospital as a voluntary exercise for this purpose. The VR 


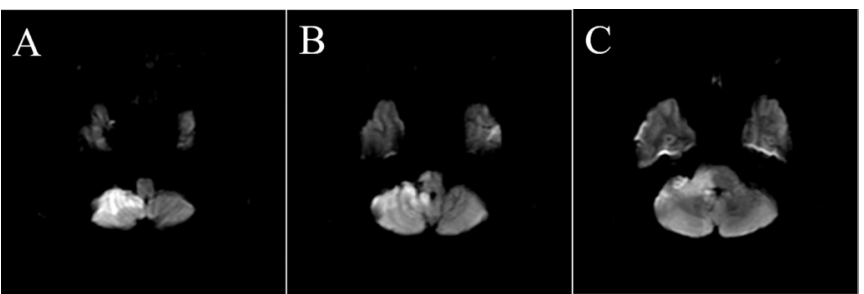

Figure 1 Diffusion-weighted cranial MRI at stroke onset. Hyperintensities are visible in the right cerebral peduncle and the ventral right cerebellar hemisphere in the area of the right anterior inferior cerebellar artery $(\mathrm{A}-\mathrm{C})$. The patient is diagnosed with right cerebellar/brainstem infarction.

rehabilitation device (mediVR KAGURA: mediVR, Toyonaka, Japan) is capable of presenting an upper limb reaching task to a user seated in three-dimensional virtual space for the purpose of body balance training; the specific task was a kind of game in which the user reaches to make contact with a series of falling objects (figure 2). VR rehabilitation was introduced to help the patient regain the level of functional balance needed to return to his job: namely, the speed, location and the number of falling objects that were customised to train him how to smoothly shift his body weight when reaching. The patient underwent this VR-guided body balance training for 2 weeks, performing two $20 \mathrm{~min}$ sets per day, 5 days a week. Exercise intensity was calibrated by adjusting the speeds, locations and numbers of falling objects. Treatment efficacy was assessed by comparing the patient's performance on several measures at baseline (admission to our hospital) with those recorded at the initial start of VR rehabilitation and after the final session. Ataxia was evaluated using the Scale for the Assessment and Rating of Ataxia (SARA). The Functional Balance Scale (FBS) was adopted to assess general balance ability and the Mini-Balance Evaluation Systems Test (Mini-BESTest) to assess more sophisticated highlevel balance skills.

\section{OUTCOME AND FOLLOW-UP}

We followed up with the patient on an outpatient basis and confirmed a successful return to work.

\section{DISCUSSION}

Ataxia can hinder movements in any number of settings, whether in daily life or social rehabilitation. ${ }^{1-3}$ Balancing skills are essential for performing job-related movements, making their recovery an inseparable part of occupational rehabilitation, in
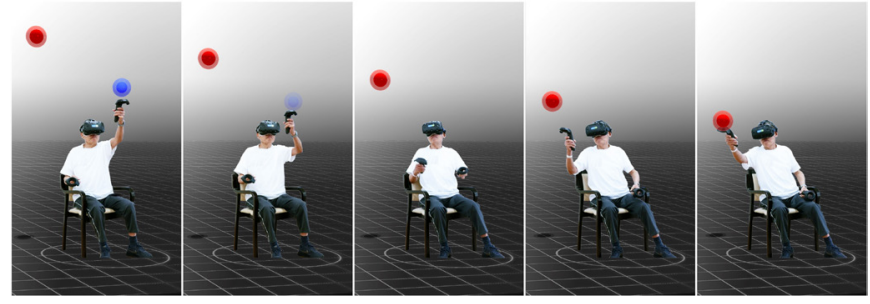

Figure 2 Visualisation of mediVR KAGURA in use: a medical device for VR-guided rehabilitation. The patient is being trained to make smooth adjustments to his centre of balance as he moves to make contact with objects falling downward in the virtual space, directly in front of his left hand, and then diagonally in front of his right hand using controllers held in the respective hand (sequence depicted from left to right). Blue and red objects must be 'caught' with the left and right hand, respectively. VR, virtual reality.

addition to motor palsy and muscle strength. However, it is difficult to state that an effective functional training methodology, along with supporting evidence, has truly been established to treat ataxia and improve balance skills, especially when it comes to high-level balancing ability in the working generation. ${ }^{12}$ This can present a problem in the rehabilitation of patients such as the present case, where working-age individuals require a highly effective yet short-term training programme to hasten their return to the workplace. For our case, a standard rehabilitation programme did not result in sufficient improvement in measures of ataxia and balance (table 1), despite its targeted content, an intensive functional training programme lasting 3 weeks following inpatient admission focused on balance training (unassisted step ups) and functional gait training (changing direction). We believe that this failure was owing to challenges adjusting the existing training methods for ataxia and balance skills to levels matching our patient's abilities. ${ }^{13} 14$ This concern led us to pursue the novel approach of VR-guided rehabilitation using a medical device, which has recently been reported effective in helping patients to recover balance-related skills after stroke or in elderly. ${ }^{89}$ We believe that some of our patient's treatment success was attributed to the effectiveness of VR-guided rehabilitation using such a device, as indicated by the record improvements in all assessment scores after VR rehabilitation (SARA, FBS, MiniBESTest) and the patient's remarks about his recovery. We also speculate that the software options available to precisely and quantitatively configure the virtual objects' attributes-including falling speed, location and count (figure 3) allowed us to resolve the usual challenges of adjusting task difficulty level encountered

Table 1 Time-series data for ataxia and balance measures

\begin{tabular}{lllll}
\hline Evaluation items & $\begin{array}{l}\text { Transfer } \\
\text { (for rehabilitation) }\end{array}$ & $\begin{array}{l}\text { First VR session } \\
\text { (3 weeks post-transfer) }\end{array}$ & $\begin{array}{l}\text { After the final VR session } \\
\text { (5 weeks post-transfer) }\end{array}$ & $\begin{array}{l}\text { Discharge } \\
\text { (7 weeks post-transfer) }\end{array}$ \\
\hline FIM total score (pts) & 101 & 124 & 125 & 126 \\
$\quad$ Motor subscale & 75 & 90 & 90 & 31 \\
$\quad$ Cognitive subscale & 26 & 34 & 35 & 35 \\
\hline FMA-lower extremity (pts) & & & 34 & 34 \\
$\quad$ Right & 30 & 33 & 34 & 34 \\
$\quad$ Left & 29 & 34 & 1 & 1 \\
SARA (pts) & 6 & 5 & 56 & 56 \\
\hline FBS (pts) & 48 & 48 & 28 & 28 \\
\hline Mini-BESTest (pts) & 20 & 20 & & \\
\hline
\end{tabular}

FBS, Functional Balance Scale; FIM, Functional Independence Measure; FMA, Fugl-Meyer Assessment; Mini-BESTest, Mini-Balance Evaluation Systems Test; SARA, Scale for the Assessment and Rating of Ataxia; VR, virtual reality. 


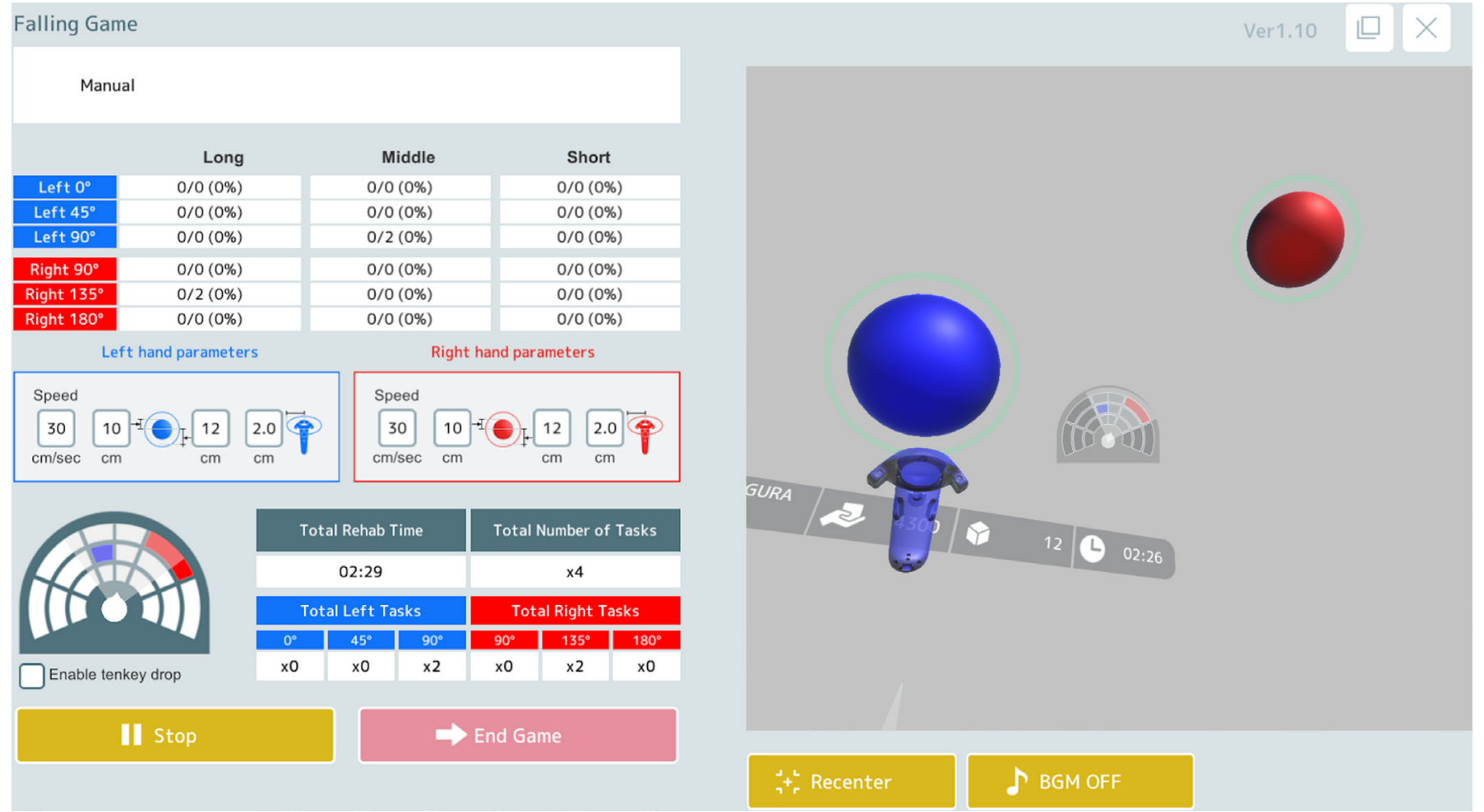

Figure 3 The computer control screen for mediVR KAGURA (in use). The speed, size, location and number of falling objects can be adjusted using the controls on the left half of the screen. Part of the rendered VR space seen by the patient is displayed on the right half of the screen. VR, virtual reality.

in traditional training exercises, leading to the patient's functional recovery. Although this report is only described a single case and distinguishing it from a natural course is challenging, sufficient improvements in SARA, FBS, Mini-BESTest after introduction of VR-guided rehabilitation implies the utility of it.

Moreover, we believe that the patient's recovery was assisted by the mediVR KAGURA's provision of accurate feedback separately for each movement on every task/trial. Specifically, this device provides the user with visual, auditory and haptic feedback when they accurately make contact with a falling object in the form of text displayed on the screen, sounds and controller vibrations, respectively. Feedforward control concerning an 'internal model' has been proposed as a powerful hypothesis for motor control by the cerebellum. ${ }^{15} 16$ 'Feedforward learning', a motor learning process involving the repetition of movements at appropriate strengths, is considered necessary to the construction of this internal model. ${ }^{2}$ Patients with cerebellar ataxia are prone to reduced feedforward control, making accurate, external feedback necessary for correcting errors, thereby potentiating feedforward learning. ${ }^{2}{ }^{17}$ However, some patients might not be able to gain sufficient feedback from the spoken remarks of therapists (as in standard rehabilitation programmes discussed above). Our patient's functional recovery can be explained in the framework of the cerebellar internal model theory as follows. The patient's immersion in the VR space permitted sensory feedback directly, in multiple forms, without any interference from the external environment. Therefore, this direct feedback fostered the feedforward learning for target movements better than conventional rehabilitation exercises. Additionally, several factors may underlie the mechanism by which seated balance training contributed to the recovery of standing balance performance: these include the fact that the upper body accounts for two-thirds of body mass, ${ }^{10}{ }^{11}$ and that the patient's lower extremities were naturally activated when he reached far beyond the base of support while seated in response to the resulting load placed on them in the direction of motion. ${ }^{11}$

VR-guided rehabilitation is highly reproducible since task speed and frequency can be precisely calibrated. It also offers objectivity and convenience, allowing practitioners to adjust the difficulty level according to an individual's characteristics and easily develop and present highly sensitive, accurate and diverse feedback. The authors have described these benefits in detail above. Taking full advantage of such next-generation technologies should expand our range of treatments as therapists, helping more patients in recovery. Nonetheless, the evidence level for this VR-guided rehabilitation programme is a single case report, indicating that the therapeutic efficacy of such exercises must still be determined in interventional research such as randomised controlled trials. Readers should also keep in mind that the patient in our case presented with a relatively infrequent rigid gait pattern when interpreting the result. However, cerebellar

\section{Learning points}

- Functional training for patients with cerebellar ataxia can be difficult in several cases, and the effective therapeutic strategies should be verified further.

- Virtual reality (VR)-guided body balance training can be a therapeutic option for the treatment of cerebellar ataxia.

- The effectiveness of VR-guided rehabilitation was indicated by the record improvements in Scale for the Assessment and Rating, Functional Balance Scale and Mini-Balance Evaluation Systems Test as well as by the patient's remarks about his recovery. 
lesions typically present with a broad-based gait. ${ }^{18} 19$ We anticipate that the promise of the VR-guided therapeutic intervention demonstrated in this case report serves to spark interventional research and foster medical progress in the field of high-level balance training of the working generation. Well-designed randomised controlled studies are needed to provide us with more accurate results in the near future.

\section{Twitter Hideo Ishikawa @2YyKj5IWqFhKDUs}

Contributors KT, KO, YM , HI contributed to the conception and design of this case report, the acquisition and interpretation of data, and drafting or revising the manuscript critically for important intellectual content.

Funding The authors have not declared a specific grant for this research from any funding agency in the public, commercial or not-for-profit sectors.

Disclaimer Case reports provide a valuable learning resource for the scientific community and can indicate areas of interest for future research. They should not be used in isolation to guide treatment choices or public health policy.

Competing interests $\mathrm{YM}$ is an employee of mediVR, a company that holds several patents on VR-guided rehabilitation. $\mathrm{KT}, \mathrm{KO}$ and $\mathrm{HI}$ have no conflicts of interest to declare.

Patient consent for publication Obtained.

Provenance and peer review Not commissioned; externally peer reviewed.

Open access This is an open access article distributed in accordance with the Creative Commons Attribution Non Commercial (CC BY-NC 4.0) license, which permits others to distribute, remix, adapt, build upon this work non-commercially, and license their derivative works on different terms, provided the original work is properly cited and the use is non-commercial. See: http://creativecommons.org/ licenses/by-nc/4.0/.

\section{REFERENCES}

1 Kelly G, Shanley J. Rehabilitation of ataxic gait following cerebellar lesions: applying theory to practice. Physiother Theory Pract 2016;32:430-7.

2 Morton SM, Bastian AJ. Mechanisms of cerebellar gait ataxia. Cerebellum 2007:6:79-86.
3 Carr JH, Shepherd RB. Neurological rehabilitation, 2nd edition. optimizing motor performance. In: Churchill Livingstone Elsevier, 2010: 217-34.

4 Masuda Y, Tei H, Shimizu S, et al. Factors associated with the misdiagnosis of cerebellar infarction. J Stroke Cerebrovasc Dis 2013;22:1125-30.

5 Edlow JA, Newman-Toker DE, Savitz SI. Diagnosis and initial management of cerebellar infarction. Lancet Neurol 2008;7:951-64.

6 Marsden J, Harris C. Cerebellar ataxia: pathophysiology and rehabilitation. Clin Rehabil 2011:25:195-216.

7 Matsugi A. Physical therapy for cerebellar ataxia. Neurological Physical Therapy 2017:157-73.

8 Li Z, Han X-G, Sheng J, et al. Virtual reality for improving balance in patients after stroke: a systematic review and meta-analysis. Clin Rehabil 2016;30:432-40.

9 de Amorim JSC, Leite RC, Brizola R, et al. Virtual reality therapy for rehabilitation of balance in the elderly: a systematic review and meta-analysis. Adv Rheumatol 2018:58:18.

10 Hara M, Kitamura T, Murakawa Y, et al. Safety and feasibility of Dual-task rehabilitation program for body trunk balance using virtual reality and threedimensional tracking technologies. Prog Rehabil Med 2018;3:n/a.

11 Omon K, Hara M, Ishikawa H. Virtual Reality-guided, Dual-task, body trunk balance training in the sitting position improved walking ability without improving leg strength. Prog Rehabil Med 2019;4:20190011:n/a.

12 Milne SC, Corben LA, Georgiou-Karistianis N, et al. Rehabilitation for individuals with genetic degenerative ataxia: a systematic review. Neurorehabil Neural Repair 2017;31:609-22.

13 Ishihara K, Hirano S, Saitoh E. Characteristics of leg muscle activity in three different tasks using the balancing exercise assist robot. Jpn J Compr Rehabil Sci 2015;6:105-12.

14 Akizuki K, Ohashi Y. Changes in practice schedule and functional task difficulty: a study using the probe reaction time technique. J Phys Ther Sci 2013;25:827-31.

15 Bastian AJ. Learning to predict the future: the cerebellum adapts feedforward movement control. Curr Opin Neurobiol 2006;16:645-9.

16 Kandel ER, Schwartz JH, Jessell TM, eds. Principles of Neural Science, Fifth Edition. The McGraw-Hill Companies, 2014

17 Pisotta I, Molinari M. Cerebellar contribution to feedforward control of locomotion. Front Hum Neurosci 2014;8:475.

18 Bakker M, Allum JHJ, Visser JE, et al. Postural responses to multidirectional stance perturbations in cerebellar ataxia. Exp Neurol 2006;202:21-35.

19 Palliyath S, Hallett M, Thomas SL, et al. Gait in patients with cerebellar ataxia. Mov Disord 1998;13:958-64.

Copyright 2021 BMJ Publishing Group. All rights reserved. For permission to reuse any of this content visit https://www.bmj.com/company/products-services/rights-and-licensing/permissions/

BMJ Case Report Fellows may re-use this article for personal use and teaching without any further permission.

Become a Fellow of BMJ Case Reports today and you can:

- Submit as many cases as you like

- Enjoy fast sympathetic peer review and rapid publication of accepted articles

- Access all the published articles

- Re-use any of the published material for personal use and teaching without further permission

Customer Service

If you have any further queries about your subscription, please contact our customer services team on +44 (0) 2071111105 or via email at support@bmj.com.

Visit casereports.bmj.com for more articles like this and to become a Fellow 